\title{
Electron Acceptors With a Truxene Core and Perylene Diimide Branches for Organic Solar Cells: The Effect of Ring-Fusion
}

Kaiwen Lin ${ }^{\dagger}$, Shiliang Wang ${ }^{\dagger}$, Zhenfeng Wang, Qingwu Yin, Xi Liu, Jianchao Jia, Xiao'e Jia, Peng Luo, Xiaofang Jiang, Chunhui Duan*, Fei Huang* and Yong Cao

State Key Laboratory of Luminescent Materials and Devices, Institute of Polymer Optoelectronic Materials and Devices, South China University of Technology, Guangzhou, China

In this work, a star-shaped planar acceptor named FTr-3PDI was synthesized via ring-fusion between truxene core and three bay-linked perylene diimide (PDI) branches. Compared to the unfused non-planar acceptor Tr-3PDI, FTr-3PDI exhibits better

\section{OPEN ACCESS}

Edited by:

Chuanlang Zhan,

Institute of Chemistry (CAS), China

Reviewed by:

Ling Teng Ye,

Harbin Institute of Technology, China

Gregory C. Welch,

University of Calgary, Canada

*Correspondence:

Chunhui Duan

duanchunhui@scut.edu.cn

Fei Huang

msfhuang@scut.edu.cn

†These authors have contributed equally to this work

Specialty section: This article was submitted to

Organic Chemistry,

a section of the journal

Frontiers in Chemistry

Received: 26 April 2018

Accepted: 12 July 2018

Published: 04 September 2018

Citation:

Lin K, Wang S, Wang Z, Yin Q, Liu X, Jia J, Jia X, Luo P, Jiang $X$, Duan $C$, Huang $F$ and Cao Y (2018) Electron Acceptors With a Truxene Core and

Perylene Diimide Branches for Organic Solar Cells: The Effect of Ring-Fusion. Front. Chem. 6:328. doi: 10.3389/fchem.2018.00328 structural rigidity and planarity, as well as more effective conjugation between truxene core and PDI branches. As a result, FTr-3PDI shows up-shifted energy levels, enhanced light absorption coefficient, increased electron mobility, and more favorable phase separation morphology in bulk-heterojunction (BHJ) blend films as compared to Tr-3PDI. Consequently, FTr-3PDI afforded higher power conversion efficiency (PCE) in BHJ solar cells when blended with a polymer donor PTB7-Th. This work demonstrates that ring-fusion is a promising molecular design strategy to combine the merits of truxene and PDI for non-fullerene acceptors used in organic solar cells.

Keywords: organic solar cells, star-shaped electron acceptors, truxene, perylene diimide, ring-fusion

\section{INTRODUCTION}

Recently, non-fullerene electron acceptors have received considerable attention in the community of organic solar cells (OSCs) due to their energy level tunability, intense optical absorption properties, and potential for low-cost and large-scale fabrication (Cheng et al., 2018; Hou et al., 2018; Yan et al., 2018). Among them, perylene diimide (PDI) derivatives are widely investigated in bulk-heterojunction (BHJ) OSCs because of their intense light absorption and high electron mobility (Zhan et al., 2007, 2011; Lin et al., 2014; Sun et al., 2015; Hendsbee et al., 2016; Liu J. et al., 2016; Liu Z. T. et al., 2016; Meng et al., 2016a). Despite these favorable properties, PDI monomer shows low device performance due to the formation of large aggregated nanostructure and undesired large crystalline domains caused by the large coplanar structure of PDI block, which hamper the exciton diffusion and separation process (Sharenko et al., 2013; Liu S. Y. et al., 2015). To overcome these drawbacks, an effective strategy is to develop non-coplanar PDI-based molecules via forming twisted intramolecular structures (Zhong et al., 2014, 2016; Lin et al., 2016; Zhang et al., 2016; Duan et al., 2017a; Liu X. et al., 2017; Liu et al., 2018). For example, a lot of star-shaped electron acceptors with PDI branches were reported recently based on this design guideline (Lin et al., 2014, 2016; Liu Y. H. et al., 2015; Lee et al., 2016; Duan et al., 2017a; Zhang A. D. et al., 2017). Although these star-shaped PDI electron acceptors can avoid forming large crystalline domains, their highly twisted architectures decrease the intermolecular contact and orbital overlapping between PDI $\pi$-planes, thus hampering electron hopping between molecules. 
Therefore, the key point to develop high-performance PDI electron acceptors is to obtain a balance between highly twisted non-planar structures for forming proper phase separation in blend films and strong intermolecular interaction for supporting sufficient charge transport ability.

Recently, several studies showed that oxidative ring-fusion between the PDI branches and the central aromatic core of PDI-based molecules is an effective strategy to achieve such an exquisite balance (Hartnett et al., 2016; Meng et al., 2016b, 2017; Zhong et al., 2016; Wang B. et al., 2017; Zhang J. Q. et al., 2017). The resulting fused PDI molecules exhibit better structural rigidity and planarity, as well as more effective conjugation between the aromatic core and PDI branches. Meanwhile, the fused PDI molecules show stronger intermolecular $\pi-\pi$ stacking and higher electron mobility. Moreover, these fused PDI acceptors can lead to desirable film morphology with proper domain size and high domain purity in $\mathrm{BHJ}$ blends when blended with donor polymers (Meng et al., 2016b, 2017; Wang B. et al., 2017; Zhang J. Q. et al., 2017). Therefore, the fused PDI acceptors display significantly improved photovoltaic performance compared to their carbon-carbon single bond connected counterparts (Scheme 1) (Li et al., 2016; Meng et al., 2016b, 2017; Liu X. F. et al., 2017; Wang B. et al., 2017; Zhang J. Q. et al., 2017). Actually, the best-performing OSCs based on PDI acceptors was achieved by a star-shaped fused PDI molecule named FTTB-PDI4, which afforded a power conversion efficiency (PCE) of 10.58\% (Zhang J. Q. et al., 2017).

Among various central cores for star-shaped electron acceptors, truxene has been proved to be promising for constructing high-performance optoelectronic materials (Nielsen et al., 2013, 2014; Lin et al., 2018; Wu et al., 2018). The rigid coplanar structure and unique $\mathrm{C}_{3 \mathrm{~h}}$ symmetry contribute to well-delocalized electronic structure in extended dimensionality for the resulting star-shaped conjugated molecules, which in turn result in strong light absorption and effective charge transport. Recently, Peng's group reported a state-of-the-art truxenebased electron acceptor for application in OSCs, which yielded impressive PCE exceeding 10\% (Wu et al., 2018). These results suggested the promising prospect of truxene for constructing high-performance electron acceptors.

Inspired by these achievements, herein, we report the design and synthesis of two star-shaped acceptors named Tr-3PDI and FTr-3PDI, (Scheme 2A) where the truxene core and PDI branches are linked by carbon-carbon single bonds or via ring-fusion, respectively. We further evaluated their potential as electron acceptors in OSCs with poly[4,8-bis(5-(2-ethylhexyl)thiophen-2-yl)benzo[1,2-b;4,5-

b]dithiophene-2,6-diyl-alt-(4-(2-ethylhexyl)-3-fluorothieno[3,4b]thiophene)-2-carboxylate-2,6-diyl] (PTB7-Th) as the donor. The solar cells based on Tr-3PDI and FTr-3PDI exhibited a PCE of 2.2 and $3.8 \%$, respectively. The better device performance of the fused acceptor FTr-3PDI is attributable to more favorable energy level alignment with the polymer donor PTB7-Th, more intense light absorption, stronger intermolecular packing, higher electron mobility, and more proper morphology in blend film. This work suggests the potential of ring-fusion strategy for constructing high performance PDI electron acceptors based on truxene core.

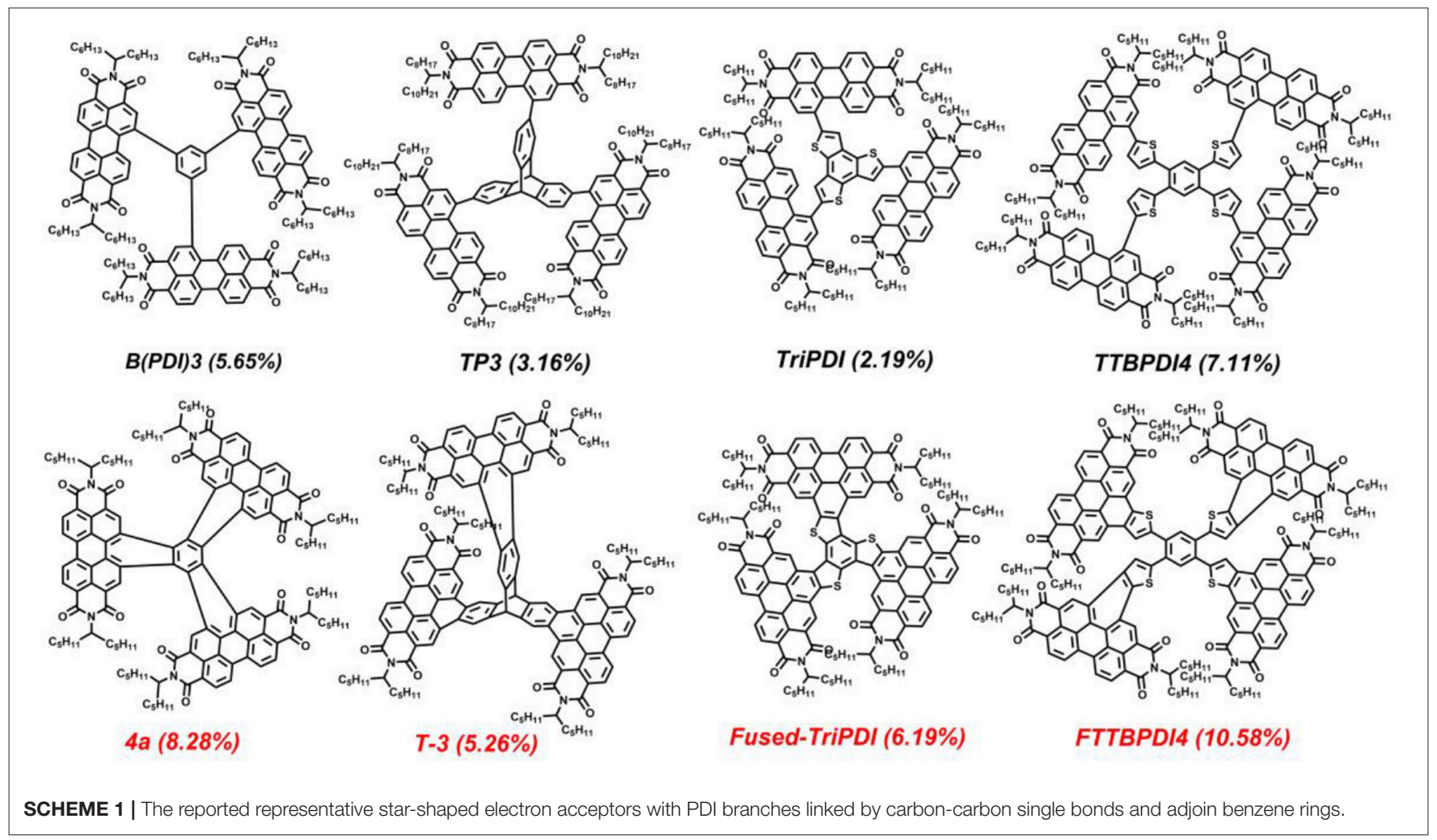




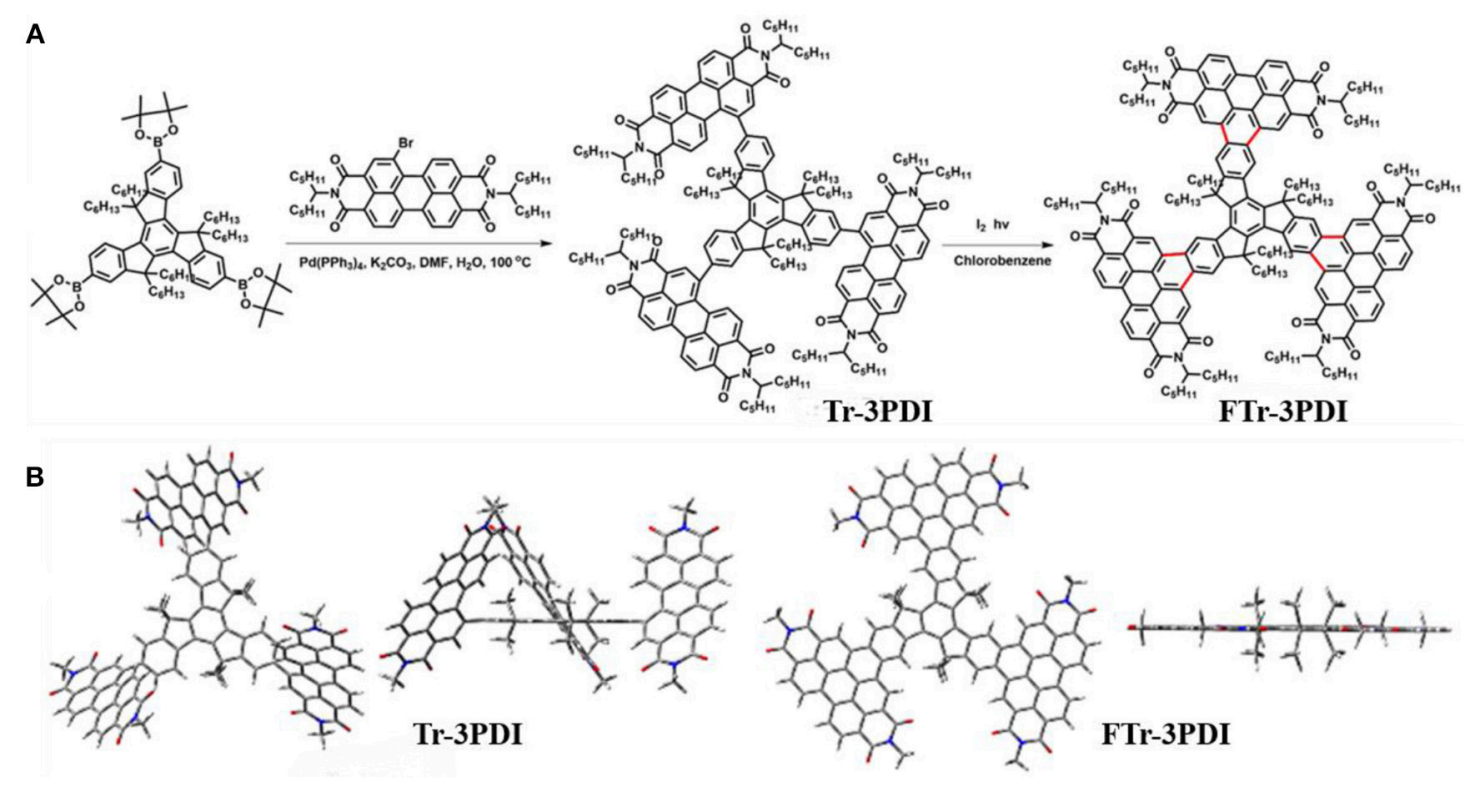

SCHEME 2 | (A) Synthetic routes and chemical structures of Tr-3PDI and Fused-Tr-3PDI; (B) views of the optimized geometries obtained using DFT calculations at the B3LYP/6-31G(d) level.

\section{EXPERIMENTAL SECTION}

\section{Materials and Synthesis}

All reagents were obtained from commercial sources and used without further purification, unless otherwise specified. Scheme $2 \mathrm{~A}$ shows the synthetic routes of Tr-3PDI and FTr3PDI. The detailed synthesis procedures are described as following.

\section{Tr-3PDI}

A mixture of $2,2^{\prime}, 2^{\prime \prime}$ - $(5,5,10,10,15,15$-hexahexyl-10,15-dihydro5H-diindeno[1,2-a: $1^{\prime}, 2^{\prime}$-c]fluorene-2,7,12-triyl)tris(4,4,5,5tetramethyl-1,3,2-dioxaborolane (truxene boronic acid pinacol ester, $0.613 \mathrm{~g}, 0.5 \mathrm{mmol})$ and 5-Bromo-2,9-bis(1pentylhexyl)anthra[2,1,9-def:6,5,10-d' $\left.\mathrm{e}^{\prime} \mathrm{f}^{\prime}\right]$ diisoquinoline-1,3,8, $10(2 \mathrm{H}, 9 \mathrm{H}$ )-tetrone (monobromo-PDI, $1.746 \mathrm{~g}, 2.25 \mathrm{mmol}$ ) in anhydrous dimethylformamide $(40 \mathrm{~mL})$ was degassed for $30 \mathrm{~min}$ before $\mathrm{Pd}\left(\mathrm{PPh}_{3}\right)_{4}(58 \mathrm{mg}, 0.05 \mathrm{mmol})$ and $\mathrm{K}_{2} \mathrm{CO}_{3}$ aqueous solution $(2 \mathrm{M}, 10 \mathrm{~mL})$ was added. The solution was heated at $95^{\circ} \mathrm{C}$ for $48 \mathrm{~h}$. Water and dichloromethane were added, and the organic layer was dried over $\mathrm{MgSO}_{4}$. After removing the solvent, the crude product was chromatographically purified on silica gel column (eluted with ethyl acetate:petrolem ether $=1: 20$ ) to afford $\mathrm{Tr}$-3PDI as a brownish-red solid $(0.95 \mathrm{~g}, 65 \%) .{ }^{1} \mathrm{H}$ NMR $\left(500 \mathrm{MHz}, \mathrm{CDCl}_{3}\right) \delta: 8.74(\mathrm{~m}, 18 \mathrm{H}), 8.60(\mathrm{~m}, 6 \mathrm{H}), 7.62(\mathrm{~m}, 6 \mathrm{H})$, $5.25(\mathrm{~m}, 6 \mathrm{H}), 3.04(\mathrm{~m}, 6 \mathrm{H}), 2.17(\mathrm{~m}, 30 \mathrm{H}), 1.29(\mathrm{~m}, 112 \mathrm{H}), 0.86$ $(\mathrm{m}, 72 \mathrm{H}) .{ }^{13} \mathrm{C}$ NMR $\left(125 \mathrm{MHz}, \mathrm{CDCl}_{3}\right) \delta: 165.00,163.91,155.86$, $155.72,146.31,142.03,141.28,140.62,138.11,135.10,134.57$, $132.77,131.59,129.98,129.46,128.77,128.34,127.78,126.99$, $126.80,123.65,122.84,122.26,56.45,56.40,54.95,54.67,37.20$, $37.07,32.52,32.34,31.91,31.84,31.83,31.81,31.59,29.85,29.80$, $29.62,29.39,26.78,26.69,24.37,24.13,22.73,22.66,22.64,22.60$,
22.50, 22.43, 14.19,14.16, 14.14. MS (MALDI-TOF) calculated for $\mathrm{C}_{201} \mathrm{H}_{246} \mathrm{~N}_{6} \mathrm{O}_{12}, 2938.21$; found, 2937.88.

\section{FTr-3PDI}

Tr-3PDI (293.7 mg, $0.1 \mathrm{mmol}$ ) was dissolved in $20 \mathrm{~mL}$ chlorobenzene before adding a catalytic amount of iodine (about $2 \mathrm{mg}$ ). The resultant mixture was stirred for $1 \mathrm{~h}$ under lab environment. After the reactivation process, kept the closed stand-up bottle exposing to irradiation of $500 \mathrm{~W}$ mercury lamp for $5 \mathrm{~h}$ at room temperature. The color of the solvent turned to brownish-yellow from brownish-red. After the reaction, the solvent was concentrated and the residue was purified by silica gel column chromatography (hexane:dichloromethane $=1: 1$ ) to afford a brownish-yellow solid (263.8 mg, 90\%). ${ }^{1} \mathrm{H}$ NMR (500 $\left.\mathrm{MHz}, \mathrm{CDCl}_{3}\right)$ 8: 10.65 $(\mathrm{m}, 9 \mathrm{H}), 9.67(\mathrm{~s}, 3 \mathrm{H}), 9.37(\mathrm{~m}, 6 \mathrm{H}), 9.17(\mathrm{~m}, 6 \mathrm{H}), 5.62(\mathrm{~m}$, $6 \mathrm{H}), 3.83(\mathrm{~m}, 6 \mathrm{H}), 3.17(\mathrm{~m}, 6 \mathrm{H}), 2.63(\mathrm{~m}, 12 \mathrm{H}), 2.10(\mathrm{~m}$, $12 \mathrm{H}), 1.47(\mathrm{~m}, 90 \mathrm{H}), 1.38(\mathrm{~m}, 15 \mathrm{H}), 0.91(\mathrm{~m}, 80 \mathrm{H}), 0.36$ $(\mathrm{m}, 18 \mathrm{H}) .{ }^{13} \mathrm{C} \mathrm{NMR}\left(125 \mathrm{MHz}, \mathrm{CDCl}_{3}\right) \delta: 165.06,164.52$, $155.41,149.23,141.71,139.02,134.27,133.92,129.76,129.33$, $128.73,127.83,127.71,125.41,125.27,124.98,123.50,123.36$, $119.83,117.66,57.60,55.26,38.26,32.81,32.03,31.56,29.57$, $27.01,24.91,22.85,22.81,22.32,14.30,14.25,13.84,13.82$. MS (MALDI-TOF) calculated for $\mathrm{C}_{201} \mathrm{H}_{240} \mathrm{~N}_{6} \mathrm{O}_{12}, 2932.16$; found, 2931.94.

\section{Instruments and Characterization}

${ }^{1} \mathrm{H}$ and ${ }^{13} \mathrm{C}$ NMR spectra were tested on a Bruker AV-500 with tetramethylsilane (TMS) as an internal reference. MALDI-TOFMS was performed by using a Bruker Agilent1290/maXis impact. UV-vis spectra were measured on a HP 8453 spectrophotometer. Thermogravimetric (TGA) analysis was measured on a 
NETZSCH TG 209 at a heating rate of $10^{\circ} \mathrm{C} \mathrm{min}^{-1}$ with a

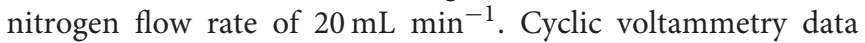
were measured on a CHI600D electrochemical workstation with $\mathrm{Bu}_{4} \mathrm{NPF}_{6}(0.1 \mathrm{M})$ in acetonitrile as the electrolyte, a carbon electrode and a saturated calomel electrode as the working and reference electrodes, respectively. The thin films were coated on a glassy carbon working electrode. The scan rate was $100 \mathrm{mV}$ $\mathrm{s}^{-1}$. The geometry was optimized by Density Functional Theory (DFT) calculations performed at the B3LYP/6-31G(d) level to optimize the ground state geometries of the acceptor molecules using the Gaussian 09. The transient photocurrent of devices was measured by applying $500 \mathrm{~nm}$ laser pulses with a pulse width of 120 fs to the devices, which produced a transient voltage signal on a $50 \Omega$ resistor and recorded by an oscilloscope (Tektronix EDS 3052C). The laser pulses were generated from optical parametric amplifier (TOPAS-Prime) pumped by a mode-locked Ti:sapphire oscillator seeded regenerative amplifier with a pulse energy of $1.3 \mathrm{~mJ}$ at $800 \mathrm{~nm}$ and a repetition rate of $1 \mathrm{KHz}$ (Spectra Physics Spitfire Ace). The atom force microscopy (AFM) images were obtained from a NanoMan VS microscopy under tapping mode. The transmission electron microscopy (TEM) images were characterized with a JEM-2100F instrument.

\section{Fabrication and Characterization of Solar Cells}

The devices of indium tin oxide (ITO)/poly(3,4ethylenedioxythiophene): poly(styrenesulfonate) (PEDOT:PSS)/ PTB7-Th:acceptor/poly[(9,9-bis(3'-((N,N-dimethyl)-Nethylammonium)-propyl)-2,7-fluorene)-alt-2,7-(9,9dioctylfluorene)]dibromide (PFN-Br)/Al were fabricated through the following procedures. The ITO-coated glass substrate was cleaned in an ultrasonic bath with deionized water, acetone, and isopropanol, each process was approximately $15 \mathrm{~min}$, and then dried under a stream of dry nitrogen. PEDOT:PSS (Heraeus Clevios PVPA 4083) was spin-coated on top of the above ITO and annealed in air at $150^{\circ} \mathrm{C}$ for 10 min. Subsequently, the blend solutions of PTB7-Th and truxene-PDI acceptors were prepared by simultaneously dissolving both materials with the optimized weight ratio in ortho-dichlorobenzene and spin-coated on the ITO/PEDOT:PSS electrode (at 1,600 rpm for $60 \mathrm{~s}$ ) to form an active layer with thickness of about $100 \mathrm{~nm}$. Then PFN-Br and Al layer were thermally deposited onto the active layer through a shadow mask at a vacuum of $5 \times 10^{-5} \mathrm{~Pa}$. During the test, an aperture with an area of $3.14 \mathrm{~mm}^{2}$ was used. The current density-voltage $(J-V)$ curves were measured on a computer-controlled Keithley 2400 source meter under 1 sun, the AM $1.5 \mathrm{G}$ spectra came from a class solar simulator (Enlitech, Taiwan), and the light intensity was $100 \mathrm{~mW} \mathrm{~cm}^{-2}$ as calibrated by a China General Certification Center-certified reference monocrystal silicon cell (Enlitech). Before the $J-V$ measurement, a physical mask with an aperture with precise area of $0.04 \mathrm{~cm}^{2}$ was used to define the device area. The external quantum efficiency (EQE) spectra were measured on a commercial QE measurement system (QE-R3011, Enlitech).

\section{Fabrication and Characterization of Single-Carrier Devices}

The charge carrier mobilities of PTB7-Th:truxene-PDI acceptor blend films were determined from single-carrier devices with space-charge-limited current (SCLC) model. The device structures of the electron only and hole only devices are ITO/ZnO/PTB7-Th:acceptor/Ca/Al and ITO/PEDOT:PSS/PTB7-Th: acceptor/ $\mathrm{MoO}_{3} / \mathrm{Ag}$ respectively. The mobilities were determined by fitting the dark $J-V$ current to the model of a single carrier SCLC using the equation: $J=$ $9 \varepsilon_{0} \varepsilon_{\mathrm{r}} \mu V^{2} / 8 d^{3}$, where $J$ is the current density, $d$ is the thickness of the blend films, $\varepsilon_{0}$ is the permittivity of free space, $\varepsilon_{\mathrm{r}}$ is the relative dielectric constant of the transport medium, and $\mu$ is the charge carrier mobility. $V=V_{\text {app }}-V_{\text {bi }}$, where $V_{\text {app }}$ is the applied voltage and $V_{\mathrm{bi}}$ is the built-in voltage. The carrier mobility can be calculated from the slope of the $J^{1 / 2}-V$ curves.

\section{RESULTS AND DISCUSSION}

\section{Synthesis and Characterization}

The synthetic routes to Tr-3PDI and FTr-3PDI are shown in Scheme 2A. Tr-3PDI was synthesized via Suzuki cross-coupling reaction between corresponding truxene boronic acid pinacol ester (Lin et al., 2018) and monobromo-PDI (Gao et al., 2017) using $\mathrm{Pd}\left(\mathrm{PPh}_{3}\right)_{4}$ as the catalyst. FTr-3PDI was obtained with an excellent yield (90\%) from Tr-3PDI by dissolving in chlorobenzene containing a catalytic amount of iodine and exposed to irradiation. Tr-3PDI and FTr-3PDI are characterized by ${ }^{1} \mathrm{H}$ NMR, ${ }^{13} \mathrm{C} \mathrm{NMR}$, and mass spectra (Figures S1-S6). The optimized geometries of Tr-3PDI and FTr-3PDI are simulated using density functional theoretical (DFT) calculations at the B3LYP/6-31G(d) level (Scheme 2B). Clearly, Tr-3PDI exhibits higher twisted structure with a large dihedral angle over $50^{\circ}$ owing to the steric hindrance effect. After the oxidative ringfusion, each PDI moiety is tethered to truxene through benzene rings, resulting in an overall planarity structure because of the high rigidity and coplanarity of truxene core. Both acceptors are soluble in common organic solvents such as dichloromethane, chloroform, chlorobenzene, and ortho-dichlorobenzene at room temperature. The reason is that there are six hexyl chains on the truxene core, providing outstanding solubility for the resulting compounds.

The thermal properties of Tr-3PDI and FTr-3PDI were analyzed by thermogravimetric analysis (TGA) and differential scanning calorimetry (DSC). As shown in Figure S7, both truxene-PDI acceptors have decomposition temperature with $5 \%$ weight loss above $400^{\circ} \mathrm{C}$. Moreover, there is no clear phase transition in DSC curves, which is indicative of the amorphous nature of Tr-3PDI and FTr-3PDI.

The UV-vis absorption spectra of the two acceptors in solutions and as thin films are shown in Figure 1A, Figure S8, and the relevant data are summarized in Table 1. Both Tr3PDI and FTr-3PDI show two absorption bands with one in the short wavelength region of $300-400 \mathrm{~nm}$ and one in the longer wavelength region of $400-600 \mathrm{~nm}$. The intense absorption in the short wavelength region is attributable to the large coplanar 

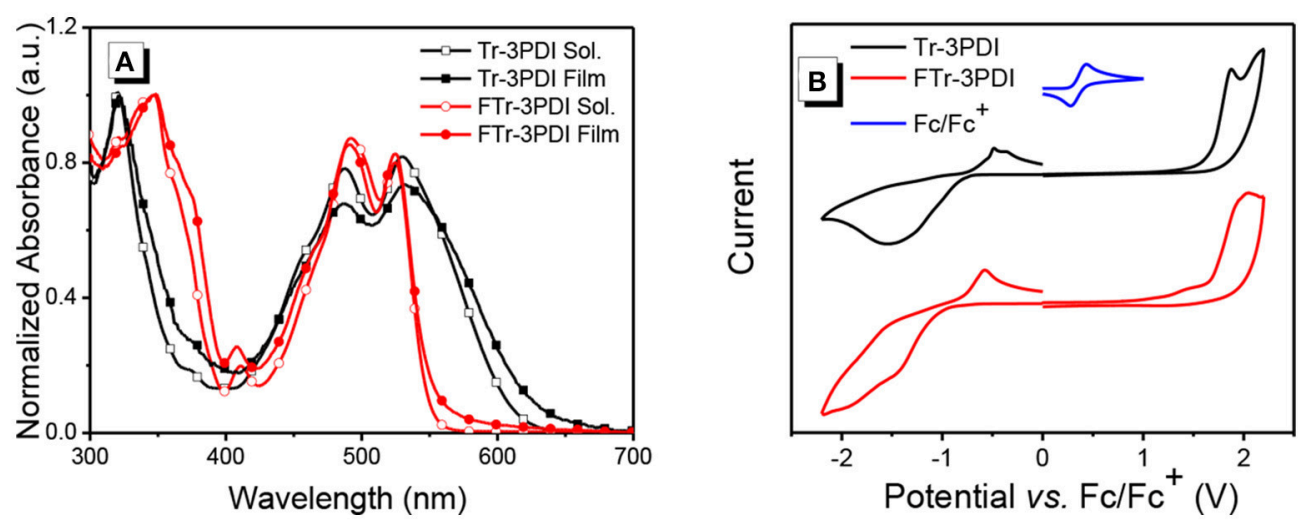

FIGURE 1 | (A) UV-vis absorption spectra of Tr-3PDI and FTr-3PDI in chloroform solutions and as thin films; (B) cyclic voltammograms of Tr-3PDI and FTr-3PDI.

TABLE 1 | Optical and electrochemical properties of Tr-3PDI and FTr-3PDI.

\begin{tabular}{lcccc}
\hline Acceptors & $\begin{array}{c}\lambda_{\text {onset }}^{\text {film }} \\
(\mathbf{n m})\end{array}$ & $\begin{array}{c}E_{\mathbf{g}}^{\text {opt a }} \\
(\mathbf{e V})\end{array}$ & $\begin{array}{c}\boldsymbol{E}_{\text {HOMO }}^{\text {boM }} \\
(\mathbf{e V})\end{array}$ & $\begin{array}{c}E_{\text {LUMO }}^{\text {c }} \\
(\mathbf{e V})\end{array}$ \\
\hline Tr-3PDI & 633 & 1.96 & -6.09 & -3.64 \\
FTr-3PDI & 556 & 2.23 & -6.11 & -3.44 \\
\hline
\end{tabular}

${ }^{a}$ Calculated from $E_{g}^{\text {opt }}=1240 / \lambda_{\text {onset }}^{\text {fim }} \mathrm{eV} ;{ }^{b}$ Calculated from $E_{\text {HOMO }}=-\mathrm{e}\left(E_{\text {OX }}^{\text {Oonse }}\right.$ $\left.E_{F C / F C+}+4.8\right) \mathrm{eV} ;{ }^{\circ}$ Calculated from $E_{L U M O}=-\mathrm{e}\left(E_{\text {red }}^{\text {Onset }}-E_{F C / F C+}+4.8\right) \mathrm{eV}$.

core of truxene. FTr-3PDI shows little difference in normalized absorption spectra from the solution state to the film state, while the solid state Tr-3PDI has extended and redshifted absorption compared to the solution state. Notably, although the two compounds have very similar absorption maxima in both solution and solid state, FTr-3PDI shows considerably blueshifted absorption onset as compared to Tr-3PDI, which could be related to the reduced conformational disorder via ring-fusion and then weakens the intramolecular charge transfer between truxene and PDI moieties. In addition, FTr-3PDI exhibits higher absorption coefficient than Tr-3PDI (Figure S8). The optical band gaps $\left(E_{\mathrm{g}}\right)$ are calculated to be $1.96 \mathrm{eV}$ for $\mathrm{Tr}-3 \mathrm{PDI}$, and $2.23 \mathrm{eV}$ for FTr-3PDI (Table 1).

The energy levels of the acceptors were determined by cyclic voltammetry $(\mathrm{CV})$ experiments. The half-wave potential of $\mathrm{Fc} / \mathrm{Fc}^{+}$was measured to be $0.36 \mathrm{~V}$, and the energy levels of the highest occupied molecular orbital (HOMO) and lowest unoccupied molecular orbital (LUMO) were estimated from the onset oxidation ( $E_{\mathrm{ox}}^{\text {onset }}$ ) and reduction ( $\left.E_{\text {red }}^{\text {onset }}\right)$ potentials by equations: $E_{\mathrm{HOMO}}=-e\left(E_{\mathrm{ox}}^{\mathrm{onset}}-E_{\mathrm{Fc} / \mathrm{Fc}}+4.8\right)$ and $E_{\mathrm{LUMO}}=$ $-e\left(E_{\text {red }}^{\text {onset }}-E_{\mathrm{Fc} / \mathrm{Fc}+}+4.8\right)$, respectively (Li et al., 1999). The $\mathrm{CV}$ curves are shown in Figure 1B, and the relevant data are listed in Table 1. The HOMO/LUMO levels are $-6.09 /-3.64 \mathrm{eV}$ for Tr-3PDI and $-6.11 /-3.44 \mathrm{eV}$ for FTr-3PDI, respectively. The slightly up-shifted LUMO level of FTr-3PDI will help to offer a higher open-circuit voltage $\left(V_{\text {oc }}\right)$, and the down-shifted HOMO level is favorable for hole transfer from excited acceptor phase to donor phase in BHJ OSCs (Duan et al., 2016a, 2017b, 2018; Jia et al., 2017).

\section{Photovoltaic Properties}

The photovoltaic properties of Tr-3PDI and FTr-3PDI were evaluated in OSCs under AM1.5G illumination at $100 \mathrm{~mW}$ $\mathrm{cm}^{-2}$ with a device structure of ITO/PEDOT:PSS/PTB7Th:acceptor/PFN-Br/Ag (Figure 2A). PTB7-Th was used as the donor because of its strong optical absorption at long-wavelength region (Figure S9), which can achieve complementary absorption with our truxene-based acceptors (Zhang et al., 2015; McAfee et al., 2017; Welsh et al., 2018). The schematic energy diagram of individual components is displayed in Figure 2B, suggesting proper energy level alignment of each layer in the device. The devices were fully optimized in terms of host solvent, donor/acceptor weight ratios, active layer thickness, solvent additives, thermal annealing, and solvent annealing. The current density-voltage $(J-V)$ curves of the optimized devices are shown in Figure 2C, and the photovoltaic parameters are summarized in Table 1. The device parameters under various conditions are collected in Tables S1-S8. The optimized device of $\mathrm{Tr}$ 3PDI afforded a PCE of $2.2 \%$ along with a $V_{\text {oc }}$ of $0.92 \mathrm{~V}$, a short-circuit current density $\left(J_{\mathrm{sc}}\right)$ of $6.5 \mathrm{~mA} \mathrm{~cm} \mathrm{~cm}^{-2}$, and a fill factor (FF) of 0.37. The ring-fused acceptor FTr-3PDI produced a higher PCE of $3.8 \%$ along with a $V_{\text {oc }}$ of $1.02 \mathrm{~V}$, a $J_{\text {sc }}$ of $8.1 \mathrm{~mA} \mathrm{~cm}^{-2}$, and an FF of 0.46 (Table 2). The higher $V_{\mathrm{oc}}$ of FTr-3PDI is consistent with the up-shifted LUMO level. The difference in $J_{\mathrm{sc}}$ of the solar cells can be explained by their external quantum efficiency (EQE) spectra (Figure 2D) (Duan et al., 2016b; Wu et al., 2016). The PTB7-Th:FTr-3PDI blend film show higher EQE than PTB7-Th:Tr-3PDI almost in the whole spectral range of $300-800 \mathrm{~nm}$, which is because of the enhanced light absorption of the former and more efficient charge generation. The PTB7-Th:FTr-3PDI device also shows higher FF than the PTB7-Th:Tr-3PDI device, suggesting improved charge transport, reduced charge recombination, and more optimal phase separated morphology (Duan et al., 2011; Xie et al., 2012).

\section{Charge Transport and Recombination}

The charge transport were investigated in single-carrier devices with a device structure of $\mathrm{ITO} / \mathrm{ZnO} /$ active layer $/ \mathrm{Ca} / \mathrm{Al}$ 

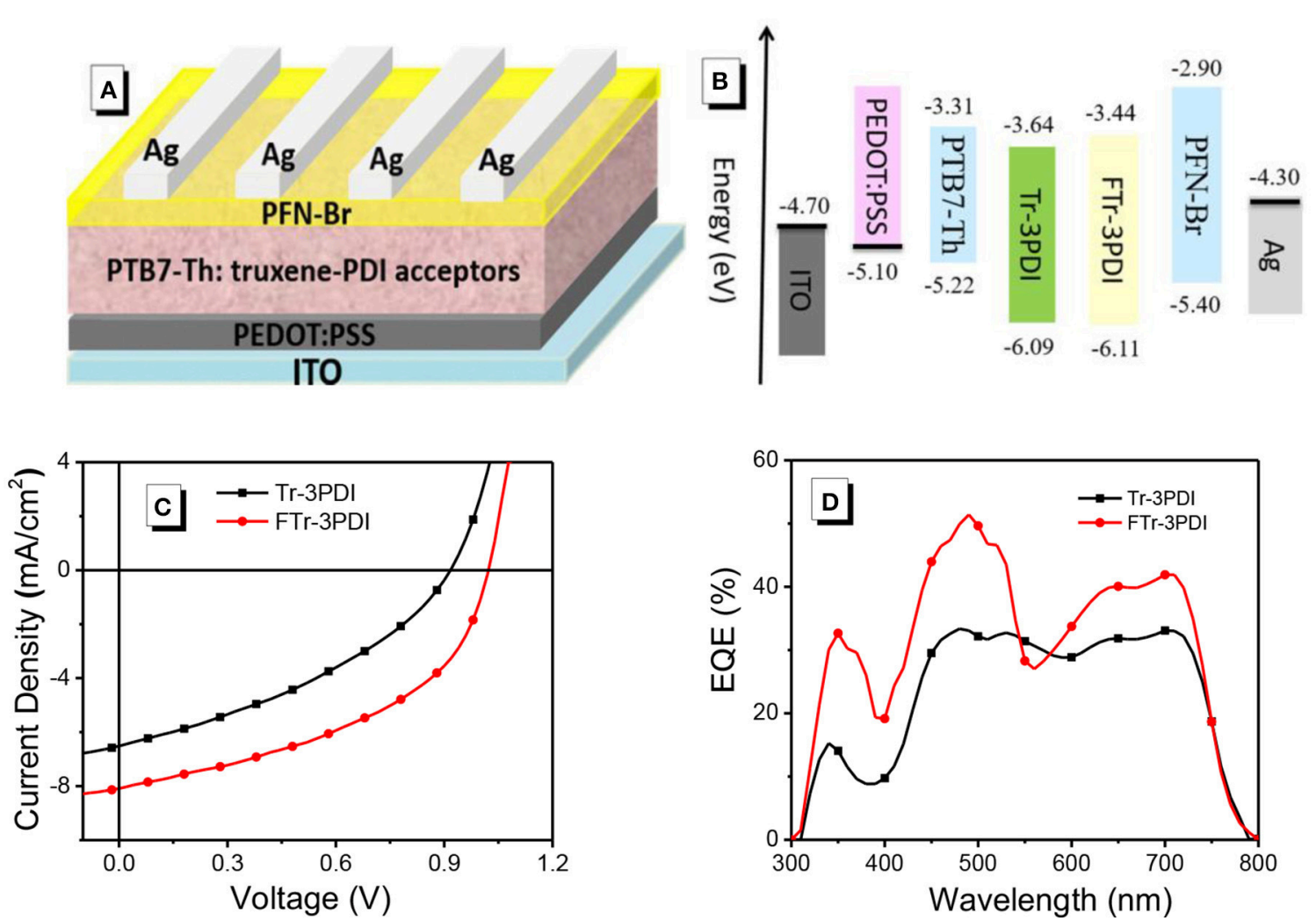

FIGURE 2 | (A) The device structure; (B) energy-level diagrams for all the materials used in this research; (C) J-V characteristics; and (D) EQE spectra of the OSCs based on PTB7-Th and truxene-PDI acceptors.

TABLE 2 | Photovoltaic parameters of OSCs based on PTB7-Th and truxene-PDI acceptors under AM1.5G illumination at $100 \mathrm{~mW} \mathrm{~cm}^{-2}$.

\begin{tabular}{lcccc}
\hline Acceptor devices & $\boldsymbol{V}_{\text {oc }}(\mathbf{V})$ & $\boldsymbol{J}_{\mathbf{s c}}\left(\mathbf{m A ~ c m}^{\mathbf{2}}\right)$ & FF & PCE (\%) \\
\hline PTB7-Th: Tr-3PDI & 0.92 & 6.5 & 0.37 & 2.2 \\
PTB7-Th: Fr-3PDI & 1.02 & 8.1 & 0.46 & 3.8 \\
\hline
\end{tabular}

for electron only devices and ITO/PEDOT:PSS/ Active layer $/ \mathrm{MoO}_{3} / \mathrm{Ag}$ for hole only devices, respectively. The electron and hole mobilities were acquired by fitting the $J-V$ with space-charge-limited current (SCLC) model. The $J-V$ curves of the devices for pure acceptors and blend films are shown in Figures S10, S11. As shown in Table 3, the FTr-3PDI pure film exhibits higher electron mobility $\left(\mu_{\mathrm{e}}\right)$ of $2.4 \times 10^{-6} \mathrm{~cm}^{2}$ $\mathrm{V}^{-1} \mathrm{~s}^{-1}$ than Tr-3PDI film $\left(3.2 \times 10^{-7} \mathrm{~cm}^{2} \mathrm{~V}^{-1} \mathrm{~s}^{-1}\right)$, which support that the ring-fusion strategy is successful. As for blend films, the hole mobilities $\left(\mu_{\mathrm{h}}\right)$ were estimated to be $1.2 \times$ $10^{-3} \mathrm{~cm}^{2} \mathrm{~V}^{-1} \mathrm{~s}^{-1}$ for PTB7-Th:Tr-3PDI and $8.2 \times 10^{-3} \mathrm{~cm}^{2}$ $\mathrm{V}^{-1} \mathrm{~s}^{-1}$ for PTB7-Th:FTr-3PDI, which are comparable with the value that obtained from PTB7-Th:fullerene devices (Huang et al., 2016). In contrast, the $\mu_{\mathrm{e}}$ of the blend films of PTB7Th:truxene-PDI acceptors were measured to be $5.8 \times 10^{-6}$ $\mathrm{cm}^{2} \mathrm{~V}^{-1} \mathrm{~s}^{-1}$ for PTB7-Th:Tr-3PDI and $1.3 \times 10^{-5} \mathrm{~cm}^{2} \mathrm{~V}^{-1}$ $\mathrm{s}^{-1}$ for PTB7-Th:FTr-3PDI, which are more than two orders of magnitude lower than that of PTB7-Th:fullerene film (Lin et al., 2015). The low electron mobility and highly imbalanced $\mu_{\mathrm{e}} / \mu_{\mathrm{h}}$ seriously obstruct the charge transport and resulted in more bimolecular recombination, which in turn led to low FF and $J_{\text {sc }}$. For the solar cells with very imbalanced $\mu_{\mathrm{e}} / \mu_{\mathrm{h}}$, the device performance will be determined by the slower charge carrier, which is electron in these cases. The higher electron mobility in PTB7-Th:FTr-3PDI will thus result in better device performance.

To study the charge-recombination of these devices, we investigated the photocurrent $\left(J_{\mathrm{sc}}\right)$ as a function of light intensity $\left(P_{\text {in }}\right.$, from 1 to $100 \mathrm{~mW} \mathrm{~cm}^{-2}$ ), with the relevant characteristics plotted in Figure 3A. Generally, $J_{\mathrm{sc}}$ and $P_{\text {in }}$ follow the relationship of $J_{\mathrm{sc}} \propto P_{\text {in }}^{S}$. If all free carriers are swept out and collected at the electrodes prior to recombination, the slope (S) should be equal to 1 , while $S<1$ indicates some extent of bimolecular recombination (Kyaw et al., 2013). The $S$-values of the two devices are 0.89 for PTB7-Th:FTr-3PDI and 0.88 for PTB7-Th:Tr-3PDI, respectively, which indicates the existence of some extent of bimolecular recombination. The charge recombination mechanism of the truxene-PDIbased OSCs are also investigated by estimating the slope $(\alpha)$ of $V_{\mathrm{oc}}$ vs. $\ln P$ ( $P$ is light intensity). In principle, the slope $\alpha$ approaching $k_{\mathrm{B}} T / q$ implies that the device has only bimolecular recombination, and the slope $\alpha$ approaching $2 k_{\mathrm{B}} T / q$ 
TABLE 3 | The relevant parameters related to charge transport and recombination of PTB7-Th: truxene-PDI acceptor devices.

\begin{tabular}{|c|c|c|c|c|c|c|}
\hline Active layer & $\mu_{h}\left(\mathrm{~cm}^{2} \mathrm{v}^{-1} \mathrm{~s}^{-1}\right)$ & $\mu_{e}\left(\mathrm{~cm}^{2} \mathrm{v}^{-1} \mathrm{~s}^{-1}\right)$ & $\mathbf{S}$ & $\alpha$ & Charge-extraction time ( $\mu s)$ & Charge carrier lifetime ( $\mu s)$ \\
\hline Tr-3PDI & - & $3.2 \times 10^{-7}$ & - & - & - & - \\
\hline FTr-3PDI & - & $2.4 \times 10^{-6}$ & - & - & - & - \\
\hline PTB7-Th:Tr-3PDI & $1.2 \times 10^{-3}$ & $5.8 \times 10^{-6}$ & 0.88 & 2.1 & 0.15 & 9.72 \\
\hline PTB7-Th:FTr-3PDI & $8.2 \times 10^{-3}$ & $1.3 \times 10^{-5}$ & 0.89 & 1.9 & 0.16 & 15.31 \\
\hline
\end{tabular}
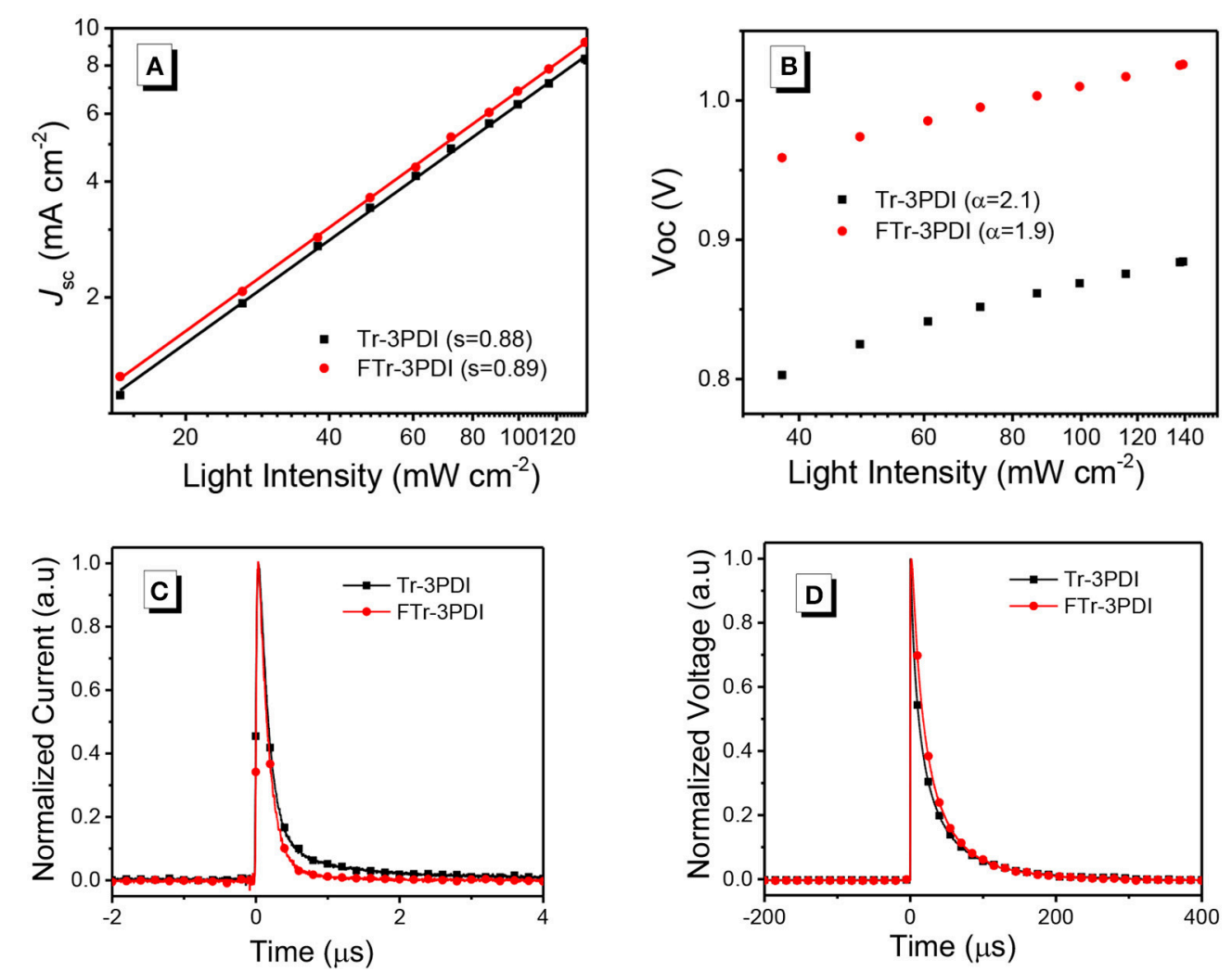

FIGURE 3 | (A) Current density vs. light intensity characteristics, and (B) open-circuit voltage vs. natural logarithm of light intensity characteristics for devices based on PTB7-Th and truxene-PDI acceptors; (C) transient photocurrent measurements; and (D) transient photovoltage of the relevant OSC devices.

suggests that the monomolecular recombination or trap-assisted recombination dominates in OSCs (where $T, k_{\mathrm{B}}$, and $q$ are the Kelvin temperature, Boltzmann constant, and elementary charge, respectively) (Koster et al., 2005; Lu et al., 2015). The $\alpha$ values for PTB7-Th:Tr-3PDI and PTB7-Th:FTr-3PDI are 2.1 and 1.9, respectively, which indicate considerable monomolecular recombination or trap-based recombination in these devices (Figure 3B and Table 3).

Transient photocurrent (TPC) and transient photovoltage (TPV) measurements were used to study the charge recombination dynamics and charge-extraction process in OSCs. From TPC analysis (Figure 3C), the charge-extraction time of the PTB7-Th:FTr-3PDI based device $(0.15 \mu \mathrm{s})$ is slightly shorter than the PTB7-Th:Tr-3PDI based device (0.16 $\mu \mathrm{s})$, suggesting increased charge extraction rate (Jin et al., 2016). From TPV analysis (Figure 3D), the charge carrier lifetime increased from $9.72 \mu \mathrm{s}$ for the PTB7-Th:Tr-3PDI device to 15.31 $\mu$ s for the PTB7-Th:FTr-3PDI device (Table 3), indicating reduced recombination loss for the PTB7-Th:FTr-3PDI device (Shuttle et al., 2008). The increased charge extraction rate and longer carrier lifetime thus explained the improved FF value and the higher PCE of the PTB7-Th:FTr-3PDI device.

\section{Morphology Characterization}

The morphology of the active layers was studied by atom force microscopy (AFM) and transmission electron microscopy (TEM). The AFM images and TEM images of the blend films are shown in Figure 4. The blend film of PTB7-Th:Tr-3PDI (Figures 4A,C) is homogeneous with a root-mean-square (RMS) surface roughness of $0.72 \mathrm{~nm}$. The uniform film reveals intimately mixed blends without noteworthy phase 

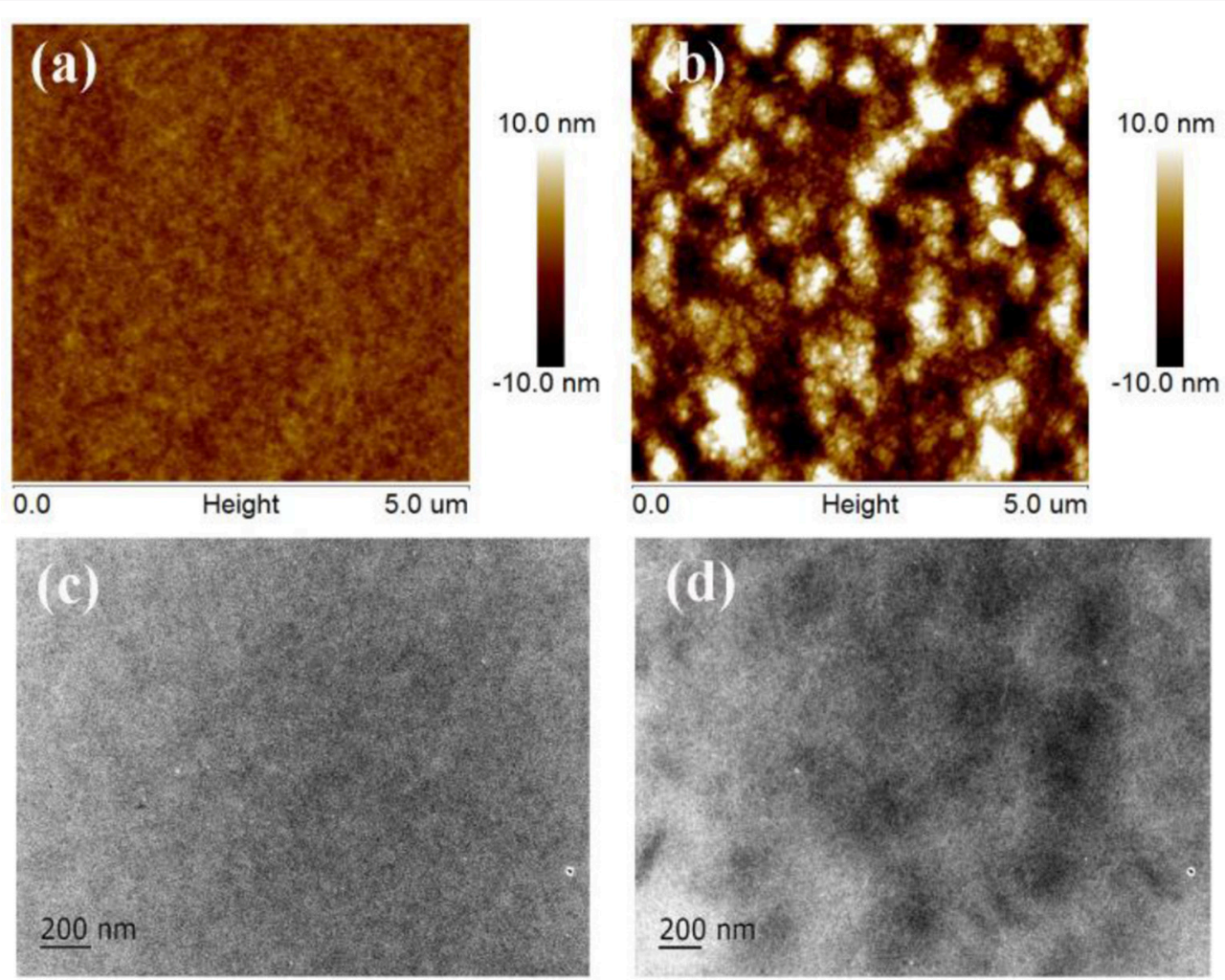

FIGURE 4 | AFM and TEM images of the blend films of PTB7-Th:truxene-PDI acceptor: (A,C) PTB7-Th:Tr-3PDI, (B,D) PTB7-Th:FTr-3PDI.

separation (Duan et al., 2017c; Wang J. Y. et al., 2017; Wen et al., 2018). With such a morphology, charge transport is impeded. The film of PTB7-Th:FTr-3PDI exhibits obvious phase separation with granulate features (Figures 4B,D), resulting in a relative coarse surface with a RMS surface roughness of $3.88 \mathrm{~nm}$. The less phase-separated morphology of PTB7Th:Tr-3PDI film could be a reason of the enhanced charge recombination and imbalanced hole/electron transport, which is in accordance with the analysis demonstrated above based on TPC, TPV, and charge carrier mobility measurements.

\section{CONCLUSION}

In summary, two electron acceptors with a truxene core and three PDIs branches linked by carbon-carbon single bonds (Tr-3PDI) or adjoin benzene ring (FTr-3PDI) are designed and developed. The FTr-3PDI shows up-shifted energy levels, enhanced absorption, improved charge mobility, and more favorable morphology as compared to $\mathrm{Tr}$-3PDI. These merits further lead to higher $V_{\mathrm{oc}}, J_{\mathrm{sc}}$, and $\mathrm{FF}$ in resulting OSCs, respectively. The OSCs of PTB7-Th:FTr-3PDI blend shows a PCE of $3.8 \%$, which is almost two times higher than that of PTB7-Th:Tr-3PDI blend. This work demonstrates a successful construction of star-shaped non-fullerene electron acceptor materials based on a truxene core and multiple PDI branches via ring-fusion to improve the performance of OSCs.

\section{AUTHOR CONTRIBUTIONS}

KL, FH and YC: Designed experiments; KL, SW, ZW, QY, XL, and XJ: Carried out experiments; JJ, XfJ, and PL: Analyzed experimental results; KL and CD: Wrote the manuscript.

\section{FUNDING}

This work was supported by the Ministry of Science and Technology (Nos. 2014CB643501, 2017YFA0206600). The research was also financially supported by the Recruitment Program of Global Youth Experts of China, the Natural Science Foundation of China (Nos. 21520102006 and 91633301).

\section{SUPPLEMENTARY MATERIAL}

The Supplementary Material for this article can be found online at: https://www.frontiersin.org/articles/10.3389/fchem. 2018.00328/full\#supplementary-material 


\section{REFERENCES}

Cheng, P., Li, G., Zhan, X. W., and Yang, Y. (2018). Next-generation organic photovoltaics based on non-fullerene acceptors. Nat. Photon. 12, 131-142. doi: 10.1038/s41566-018-0104-9

Duan, C. H., Franeker, J. J., Wienk, M., and Janssen, R. A. J. (2016b). High open circuit voltage polymer solar cells enabled by employing thiazoles in semiconducting polymers. Polym. Chem. 7, 5730-5738. doi: 10.1039/c6py01083k

Duan, C. H., Gao, K., Colberts, F. J. M., Liu, F., Meskers, S. C. J., Janssen, R. A. J., et al. (2017b). Thiophene rings improve the device performance of conjugated polymers in polymer solar cells with thick active layers. Adv. Energy Mater. 7:1700519. doi: 10.1002/aenm.201700519

Duan, C. H., Guzmán, D., Colberts, F. J. M., Janssen, R. A. J., and Torres, T. (2018). Subnaphthalocyanines as electron acceptors in polymer solar cells: improving device performance by modifying peripheral and axial substituents. Chem. Eur. J. 24, 1-6. doi: 10.1002/chem.201800596

Duan, C. H., Wang, C. D., Liu, S. J., Huang, F., Choy, C. H. W., and Cao, Y. (2011). Two-dimensional like conjugated copolymers for high efficiency bulkheterojunction solar cell application: band gap and energy level engineering. Sci. China Chem. 54, 685-694. doi: 10.1007/s11426-011-4257-3

Duan, C. H., Willems, R. E. M., Franeker, J. J., Bruijnaers, B. J., Wienk, M. M., and Janssen, R. A. J. (2016a). Effect of side chain length on the charge transport, morphology, and photovoltaic performance of conjugated polymers in bulk heterojunction solar cells. J. Mater. Chem. A 4, 1855-1866. doi: $10.1039 / \mathrm{c} 5 \mathrm{ta} 09483 \mathrm{f}$

Duan, C. H., Zango, G., Iglesias, M. G., Martínez-Díaz, M. V., Janssen, R. A. J., Torres, T., et al. (2017c). The role of the axial substituent in subphthalocyanine acceptors for bulk-heterojunction solar cells. Angew. Chem. Int. Ed. 56, 148-152. doi: 10.1002/anie.201608644

Duan, Y. W., Xu, X. P., Yan, H., Wu, W. L., Li, Z. J., and Peng, Q. (2017a). Pronounced effects of a triazine core on photovoltaic performance-efficient organic solar cells enabled by a PDI trimer-based small molecular acceptor. Adv. Mater. 29:1605115. doi: 10.1002/adma.201605115

Gao, G. P., Liang, N. N., Geng, H., Jiang, W., Fu, H. T., Wang, Z. H., et al. (2017). Spiro-fused perylene diimide arrays. J. Am. Chem. Soc. 139, 15914-11592. doi: 10.1021/jacs.7b09140

Hartnett, P. E., Matte, H. S. S. R., Eastham, N. D., Jackson, N. E., Wasielewski, M. R., Marks, T. J., et al. (2016). Ring-fusion as a perylenediimide dimer design concept for high-performance non-fullerene organic photovoltaic acceptors. Chem. Sci. 7, 3543-3555. doi: 10.1039/c5sc04956c

Hendsbee, A. D., Sun, J. P., Law, W. K., Yan, H., Hill, I. G., and Welch, G., C. et al. (2016). Synthesis, self-assembly, and solar cell performance of $\mathrm{N}$-annulated perylene diimide non-fullerene acceptors. Chem. Mater. 28, 7098-7109. doi: 10.1021/acs.chemmater.6b03292

Hou, J. H., Inganäs, O., Friend, R. H., and Gao, F. (2018). Organic solar cells based on non-fullerene acceptors. Nat. Mater. 17, 119-128. doi: 10.1038/NMAT5063

Huang, J., Carpenter, J. H., Li, C. Z., Yu, J. S., Ade, H., and Jen, A. K.-Y. (2016). Highly efficient organic solar cells with improved vertical donor-acceptor compositional gradient via an inverted off-center spinning method. Adv. Mater. 28, 967-974. doi: 10.1002/adma.201504014

Jia, J. C., Zheng, N. N., Wang, Z. F., Huang, Y. P., Duan, C. H., Huang, F., et al. (2017). The effect of end-capping groups in A-D-A type non-fullerene acceptors on device performance of organic solar cells. Sci. China Chem. 60, 1458-1467. doi: $10.1007 / \mathrm{s} 11426-017-9102-1$

Jin, Y. C., Chen, Z. M., Dong, S., Zheng, N. N., Ying, L., Huang, F., et al. (2016). A novel naphtho[1,2-c:5,6-c']Bis([1,2,5]Thiadiazole)-based narrow-bandgap $\pi$ conjugated polymer with power conversion efficiency over 10\%. Adv. Mater. 28, 9811-9818. doi: 10.1002/adma.201603178

Koster, L. J. A., Mihailetchi, V. D., Ramaker, R., and Blom, P. W. M. (2005). Light intensity dependence of open-circuit voltage of polymer:fullerene solar cells. Appl. Phys. Lett. 86:123509. doi: 10.1063/1.1889240

Kyaw, A. K. K., Wang, D. H., Wynands, D., Zhang, J., Nguyen, T. Q., Bazan, G. C., et al. (2013). Improved light harvesting and improved efficiency by insertion of an optical spacer $(\mathrm{ZnO})$ in solution-processed small-molecule solar cells. Nano Lett. 13, 3796-3801. doi: 10.1021/nl401758g

Lee, J., Singh, R., Sin, D. H., Kim, H. G., Song, K. C., and Cho, K. (2016). A nonfullerene small molecule acceptor with 3D interlocking geometry enabling efficient organic solar cells. Adv. Mater. 28, 69-76. doi: 10.1002/adma.201504010

Li, S. X., Liu, W. Q., Li, C. Z., Liu, F., Chen, H. Z., Russelld, T. P., et al. (2016). A simple perylene diimide derivative with a highly twisted geometry as an electron acceptor for efficient organic solar cells. J. Mater. Chem. A 4, 10659-10665. doi: 10.1039/c6ta04232e

Li, Y. F., Cao, Y., Gao, J., Wang, D. L., Yu, G., and Heeger, A. J. (1999). Electrochemical properties of luminescent polymers and polymer light-emitting electrochemical cells. Synth. Met. 99, 243-248. doi: 10.1016/S0379-6779(99)00007-7

Lin, H. R., Chen, S. S., Hu, H. W., Zhang, L., Ma, T. X., and Yan, H. (2016). Reduced intramolecular twisting improves the performance of 3D molecular acceptors in non-fullerene organic solar cells. Adv. Mater. 28, 8546-8551. doi: 10.1002/adma.201600997

Lin, K. W., Xie, B. M., Wang, Z. F., Duan, C. H., Huang, F., Cao, Y., et al. (2018). Star-shaped electron acceptors containing a truxene core for non-fullerene solar cells. Org. Electron. 52, 42-50. doi: 10.1016/j.orgel.2017. 10.009

Lin, Y. Z., Wang, J. Y., Zhang, Z. G., Bai, H. T., Li, Y. F., Zhu, D. B., et al. (2015). An electron acceptor challenging fullerenes for efficient polymer solar cells. Adv. Mater. 27, 1170-1174. doi: 10.1002/adma.201404317

Lin, Y. Z., Wang, Y. F., Wang, J. Y., Hou, J. H., Li, Y. F., Zhu, D. B., et al. (2014). A star-shaped perylene diimide electron acceptor for high-performance organic solar cells. Adv. Mater. 26, 5137-5142. doi: 10.1002/adma.2014 00525

Liu, J., Chen, S. S., Qian, D. P., Gautam, B., Gundogdu, K., Gao, F., Yan, H., et al. (2016). Fast charge separation in a non-fullerene organic solar cell with a small driving force. Nat. Energy 1, 1-7. doi: 10.1038/NENERGY.2016.89

Liu, S. Y., Wu, C. H., Li, C. Z., Liu, S. Q., Wei, K. H., Chen, H. Z., et al. (2015). A tetraperylene diimides based 3D nonfullerene acceptor for efficient organic photovoltaics. Adv. Sci. 2:1500014. doi: 10.1002/advs.201500014

Liu, X., Liu, T., Duan, C. H., Sun, Y. M., Huang, F., Cao, Y., et al. (2017). Nonplanar perylenediimide acceptors with different geometrical linker units for efficient nonfullerene organic solar cells. J. Mater. Chem. A 5, 1713-1723. doi: 10.1039/c6ta08739f

Liu, X. F., Cai, Y. H., Huang, X. B., Zhang, R. B., and Sun, X. B. (2017). A perylene diimide electron acceptor with a triptycene core for organic solar cells. J. Mater. Chem. C 5, 3188-3194. doi: 10.1039/c7tc00378a

Liu, Y. H., Mu, C., Jiang, K., Zhao, J. B., Li, Y. K., Yan, H., et al. (2015). A tetraphenylethylene core-based 3D structure small molecular acceptor enabling efficient non-fullerene organic solar cells. Adv. Mater. 27, 1015-1020. doi: 10.1002/adma.201404152

Liu, Z. T., Wu, Y., Zhang, Q., and Gao, X. (2016). Non-fullerene small molecule acceptors based on perylene diimides. J. Mater. Chem. A 4, 17604-17622. doi: $10.1039 /$ c6ta06978a

Liu, Z. T., Zhang, L. H., Shao, M., Wu, Y., Zeng, D., Gao, X., et al. (2018). Finetuning the quasi-3D geometry: enabling efficient nonfullerene organic solar cells based on perylene diimides. ACS Appl. Mater. Interfaces 10, 762-768. doi: 10.1021/acsami.7b16406

Lu, L. Y., Chen, W., Xu, T., and Yu, L. P. (2015). High-performance ternary blend polymer solar cells involving both energy transfer and hole relay processes. Nat. Commun. 6:7327. doi: 10.1038/ncomms8327

McAfee, S. M., Dayneko, S. V., Josse, P., Blanchard, P., Cabanetos, C., and Welch, G. C. (2017). Simply complex: the efficient synthesis of an intricate molecular acceptor for high-performance air-processed and air-tested fullerene-free organic solar cells. Chem. Mater. 29, 1309-1314. doi: 10.1021/acs.chemmater.6b04862

Meng, D., Fu, H. T., Fan, B. B., Li, Y., Sun, Y. M., Wang, Z. H., et al. (2017). Rigid nonfullerene acceptors based on triptycene-perylene dye for organic solar cells. Chem. Asian J. 12, 1286-1290. doi: 10.1002/asia.201700440

Meng, D., Fu, H. T., Xiao, C. Y., Meng, X. Y., Sun, Y. M., Wang, Z. H., et al. (2016b). Three-bladed rylene propellers with three-dimensional network assembly for organic electronics. J. Am. Chem. Soc. 138, 10184-10190. doi: 10.1021/jacs.6b04368

Meng, D., Sun, D., Zhong, C. M., Sun, Y. M., Wang, Z. H., et al. (2016a). Highperformance solution-processed non-fullerene organic solar cells based on selenophene-containing perylene bisimide acceptor. J. Am. Chem. Soc. 138, 375-380. doi: 10.1021/jacs.5b11149 
Nielsen, C. B., Voroshazi, E., Holliday, S., Cnops, K., Cheyns, D., and McCulloch, I. (2014). Electron-deficient truxenone derivatives and their use in organic photovoltaics. J. Mater. Chem. A 2, 12348-12354. doi: 10.1039/c4ta $01653 \mathrm{j}$

Nielsen, C. B., Voroshazi, E., Holliday, S., Cnops, K., Randb, B. P., and McCulloch, I. (2013). Efficient truxenone-based acceptors for organic photovoltaics. J. Mater. Chem. A 1, 73-76. doi: 10.1039/c2ta00548d

Sharenko, A., Proctor, C. M., Poll, T. S. V., Henson, Z. B., Nguyen, T.-Q., and Bazan, G. C. (2013). A high-performing solution-processed small molecule: perylene diimide bulk heterojunction solar cell. Adv. Mater. 25, 4403-4406. doi: 10.1002/adma.201301167

Shuttle, C. G., O’Regan, B., Ballantyne, A. M., Nelson, J., Bradley, D. D. C., de Mello, J., et al. (2008). Experimental determination of the rate law for charge carrier decay in a polythiophene: fullerene solar cell. Appl. Phys. Lett. 92:093311. doi: 10.1063/1.2891871

Sun, D., Meng, D., Cai, Y. H., Huo, L. J., Sun, Y. M., Wang, Z. H., et al. (2015). Nonfullerene-acceptor-based bulk-heterojunction organic solar cells with efficiency over 7\%. J. Am. Chem. Soc. 137, 11156-11162. doi: 10.1021/jacs.5b06414

Wang, B., Liu, W. Q., Li, H. B., Mai, J. Q., Li, C. Z., Chen, H. Z., et al. (2017). Electron acceptors with varied linkages between perylene diimide and benzotrithiophene for efficient fullerene-free solar cells. J. Mater. Chem. A 5, 9396-9401. doi: 10.1039/C7TA02582C

Wang, J. Y., Wang, S. L., Duan, C. H., Lu, X. H., Janssen, R. A. J., Huang, F., et al. (2017). Conjugated polymers based on difluorobenzoxadiazole toward practical application of polymer solar cells. Adv. Energy Mater. 7:1702033. doi: 10.1002/aenm.201702033

Welsh, T. A., Laventure, A., Baumgartner, T., and Welch, G. C. (2018). Dithienophosphole-based molecular electron acceptors constructed using direct (hetero)arylation cross-coupling methods. J. Mater. Chem. C 6, 2148-2154. doi: 10.1039/c7tc05631a

Wen, S. G., Wu, Y., Wang, Y. Y., Li, Y., Liu, Z. T., Yang, R. Q., et al. (2018). Pyranbridged indacenodithiophene as a building block for constructing efficient AD-A-type nonfullerene acceptors for polymer solar cells. ChemSusChem 11, 360-366. doi: 10.1002/cssc.201701917

Wu, W. L., Zhang, G. J., Xu, X. P., Wang, S. C., Li, Y., and Peng, Q. (2018). Wide bandgap molecular acceptors with a truxene core for efficient nonfullerene polymer solar cells: linkage position on molecular configuration and photovoltaic properties. Adv. Funct. Mater. 28, 1707493. doi: 10.1002/adfm.201707493

Wu, Z. H., Zhu, Y. X., Li, W., Huang, Y. P., Duan, C. H., Huang, F., et al. (2016). Design, synthesis and photovoltaic properties of a series of new acceptor-pended conjugated polymers. Sci. China Chem. 59, 1583-1592. doi: 10.1007/s11426-016-0203-5

Xie, H. M., Zhang, K., Duan, C. H., Liu, S. J., Huang, F., and Cao, Y. (2012). New acceptor-pended conjugated polymers based on 3,6- and 2,7-carbazole for polymer solar cells. Polymer 53, 5675-5683. doi: 10.1016/j.polymer.2012. 10.008

Yan, C. Q., Barlow, S., Wang, Z. H., Yan, H., Jen, A. K.-Y., Marder, S. R., et al. (2018). Non-fullerene acceptors for organic solar cells. Nat. Rev. Mater. 3:18003. doi: 10.1038/natrevmats.2018.3

Zhan, X. W., Facchetti, A., Barlow, S., Marks, T. J., Ratner, M. A., Wasielewski, M. R., et al. (2011). Rylene and related diimides for organic electronics. Adv. Mater. 23, 268-284. doi: 10.1002/adma.201001402

Zhan, X. W., Tan, Z. A., Domercq, B., An, Z. S., Zhang, X., Barlow, S., et al. (2007). A high-mobility electron-transport polymer with broad absorption and its use in field-effect transistors and all-polymer solar cells. J. Am. Chem. Soc. 129, 7246-7247. doi: 10.1021/ja071760d

Zhang, A. D., Li, C., Yang, F., Zhang, J. Q., Wang, Z. H., Wei, Z. X., et al. (2017). An electron acceptor with porphyrin and perylene bisimides for efficient non-fullerene solar cells. Angew. Chem. Int. Ed. 56, 2694-2698. doi: 10.1002/anie.201612090

Zhang, J. Q., Li, Y. K., Huang, J. C., Hu, H. W., Zhang, G. Y., Yan, H.e., et al. (2017). Ring-fusion of perylene diimide acceptor enabling efficient nonfullerene organic solar cells with a small voltage loss. J. Am. Chem. Soc. 139, 16092-16095. doi: 10.1021/jacs.7b09998

Zhang, X., Yao, J. N., and Zhan, C. L. (2016). Synthesis and photovoltaic properties of low bandgap dimeric perylene diimide based non-fullerene acceptors. Sci. China Chem. 59, 209-217. doi: 10.1007/s11426-015-5485-8

Zhang, X., Zhan, C. L., and Yao, J. N. (2015). Non-fullerene organic solar cells with $6.1 \%$ efficiency through fine-tuning parameters of the film-forming process. Chem. Mater. 27, 166-173. doi: 10.1021/cm504140c

Zhong, H. L., Wu, C. H., Li, C. Z., Carpenter, J., Chueh, C.-C., Jen, A. K.-Y. et al. (2016). Rigidifying nonplanar perylene diimides by ring fusion toward geometry-tunable acceptors for high-performance fullerene-free solar cells. Adv. Mater. 28, 951-958. doi: 10.1002/adma.201504120

Zhong, Y. U., Trinh, M. T., Xiao, S. X., Ng, F., Zhu, X. Y., Nuckolls, C., et al. (2014). Efficient organic solar cells with helical perylene diimide electron acceptors. J. Am. Chem. Soc. 136, 15215-15221. doi: 10.1021/ja5092613

Conflict of Interest Statement: The authors declare that the research was conducted in the absence of any commercial or financial relationships that could be construed as a potential conflict of interest.

Copyright (c) 2018 Lin, Wang, Wang, Yin, Liu, Jia, Jia, Luo, Jiang, Duan, Huang and Cao. This is an open-access article distributed under the terms of the Creative Commons Attribution License (CC BY). The use, distribution or reproduction in other forums is permitted, provided the original author(s) and the copyright owner(s) are credited and that the original publication in this journal is cited, in accordance with accepted academic practice. No use, distribution or reproduction is permitted which does not comply with these terms. 